УДК 343.144

Г. В. Сорокин

Байкальский государственный университет, г. Иркутск, Российская Федерация

\title{
ЗНАЧЕНИЕ ПРИЗНАНИЯ ВИНЫ В РОССИЙСКОМ УГОЛОВНОМ СУДОПРОИЗВОДСТВЕ
}

\begin{abstract}
АНнотАция. В дореволюционный период российского уголовного судопроизводства ценнейшим доказательством было признание вины обвиняемого, которое часто добывалось путем пыток. В современном уголовном судопроизводстве данные методы неприемлемы, поэтому в статье обсуждается вопрос применения к обвиняемым незаконных методов ведения допроса. Рассматриваются пути решения проблемы применения незаконных методов ведения допроса на досудебной стадии производства по уголовному делу, предложенные разными авторами. Особое внимание уделяется роли и месту признательных показаний обвиняемого в связи с иными уголовно-процессуальными институтами, которые имеют связь с данным видом доказательств. Отстаивается точка зрения об исключении признательных показаний обвиняемого из перечня доказательств. Таким образом, это позволит исключить применение насилия на досудебной стадии производства по уголовному делу к обвиняемому и обеспечить соблюдение его прав, гарантированных Уголовно-процессуальным кодексом РФ.

кЛючЕВЫЕ СЛОВА. Доказательства; обвиняемый; допрос; показания обвиняемого; признание вины; незаконные методы допроса.

ИНФОРМАЦИЯ О СТАТЬЕ. Дата поступления 10 мая 2016 г.; дата принятия к печати 21 июня 2016 г.; дата онлайн-размещения 30 сентября 2016 г.
\end{abstract}

G. V. Sorokin

Baikal State University, Irkutsk, Russian Federation

\section{SIGNIFICANCE OF CONFESSING GUILT IN RUSSIAN CRIMINAL PROCEDURE}

ABSTRACT. If during the pre-revolutionary period of Russian criminal procedure the most valuable evidence was confession of guilt by the accused often obtained by means of torture. In modern criminal procedure such methods are inacceptable, so the article discusses the problem of applying illegal methods of interrogation towards the accused. It considers the ways of solving the problem of applying illegal methods of interrogation at the pre-trial stage of the criminal case procedure offered by various authors, giving a particular attention to the role and place of admissions in view of other criminal procedure institutions which are connected with such type of evidences. The article maintains a of excluding the admissions of the accused from the evidences. So, it will allow to prevent the use of force at the pre-trial stage of criminal in regard of the accused and provide observance of his rights guaranteed by the Criminal Procedure Code of the Russian Federation of Russian Federation.

KEYWORDS. Evidences; the accused; interrogation; statement of the accused; confession of guilt; illegal interrogation methods.

ARTICLE INFO. Received May 10, 2016; accepted June 21, 2016; available online September $30,2016$.

Лучше освободить от наказания десять виновных, нежели приговорить одного невиновного.

Свод законов Российской илперии (cm.1176)

Уголовно-процессуальный кодекс РФ (УПК РФ) рассматривает показания обвиняемого как один из видов доказательств. Отметив в ч. 2 ст. 17 УПК РФ, что «никакие доказательства не имеют заранее установленной силы», в ч. 2 ст. 77 УПК РФ

(C) Г. В. Сорокин, 2016

\section{Baikal Research Journal}


законодатель дублирует данную норму, отмечая особую значимость данного вида доказательств.

В УПК РФ показания обвиняемого трактуются как сведения, сообщенные им на допросе, проведенном в ходе досудебного производства по уголовному делу или в суде в соответствии с требованиями ст. 173, 174, 187-190, 275 УПК РФ (ч. 1 ст. 77 УПК РФ). Из этого следует, во-первых, показания обвиняемого - это сведения, на основании которых суд, прокурор, следователь, дознаватель в порядке, определенном кодексом, устанавливает наличие или отсутствие обстоятельств, подлежащих доказыванию при производстве по уголовному делу, а также иных обстоятельств, имеющих значение для уголовного дела (ч. 1 ст. 74 УПК РФ). Во-вторых, данные сведения должны быть сообщены обвиняемым на допросе, проведенном в ходе досудебного производства по уголовному делу или в суде. В уголовно-процессуальном законодательстве не дается определения такому следственному действию, как допрос. Законодатель лишь перечисляет его признаки: место, время, порядок вызова на допрос, общие правила проведения, а также способ его процессуального закрепления с помощью протокола.

Обратившись к Уставу уголовного судопроизводства 1864 г. (далее -УУС), а именно к ст. 406, которая применительно к предмету настоящего исследования представляет наибольший интерес, найдем следующее положение: «если обвиняемый откажется отвечать на данные ему вопросы, то следователь, отметив о том в протоколе, изыскивает другие законные средства к открытию истины» [1, с. 160], при этом следователь не должен «домогаться сознания обвиняемого ни обещаниями, ни ухищрениями, ни угрозами или тому подобными мерами вымогательства».

В ст. 139 УПК РСФСР 1922 г. также было установлено, что следователь не имеет права домогаться показания или сознания обвиняемого путем насилия, угроз и других подобных мер. УПК РФ, в отличие от УУС и УПК РСФСР 1922 г., не содержит данной нормы, что является весьма удивительным, имеются лишь общие нормы: ч. 3 и 4 ст. 11 УПК РФ, ч. 4 ст. 164 УПК РФ об общих правилах производства следственных действий, содержащие запрет на насилие, угрозы и иные незаконные меры воздействия.

Однако так или иначе, использование на досудебной стадии незаконных методов допроса для получения признательных показаний не редкость на сегодняшний день. Связано это в первую очередь с системой «галочек» в деятельности правоохранительных органов, а также с ошибочным мнением, что признание обвиняемым своей вины есть наиболее ценное доказательство. В этой связи И. В. Смолькова пишет: «с большим сожалением приходится признать, что в следственной практике до сих пор не изжиты случаи применения к подозреваемым и обвиняемым психического или физического насилия для получения признательных показаний. Угрозы и шантаж, физическое воздействие, избиения, издевательства, пытки и даже садистские методы (например, случай издевательств в УВД «Северный» в Казани) стали довольно привычными явлениями нашей досудебной практики» [2, с. 8].

Одна из основных целей использования незаконных методов допроса, конечно же, стремление получить признательные показания обвиняемого как доказательство вины.

В науке уголовно-процессуального права существуют различные взгляды на роль и место показаний обвиняемого в системе доказательств. Так, Р. Куссмауль считает, что если в уголовном деле из доказательств имеются только показания обвиняемого, подсудимого, то они всегда сомнительны, но если имеет место быть совокупность доказательств, то показания обвиняемого, подсудимого не нужны вообще. Исходя из этого, показания обвиняемого должны быть исключены из числа доказательств [3, с. 53]. Трудно согласиться с данной точкой зрения, так как показания

\section{Baikal Research Journal}


обвиняемого по уголовному делу являются средством защиты от предъявленного обвинения. Согласно п. 6 ст. 47 УПК РФ обвиняемый не обязан, а именно имеет право давать показания и объясняться на родном языке или языке, которым он владеет после предъявления обвинения. С учетом того, что в ст. 307 Уголовного кодекса (УК РФ) обвиняемый не указан в качестве субъекта преступления за дачу заведомо ложных показаний, следует заключить, что обвиняемый имеет право лгать.

Обвиняемый имеет право встречаться с защитником наедине и конфиденциально, в том числе до первого допроса обвиняемого, без ограничения их числа и продолжительности (п. 9 ст. 47 УПК РФ). На данном этапе защитник может помочь выстроить показания в выгодном для своего клиента ракурсе. Данный способ является эффективным и не нарушает закон. Как установлено в ст. 45 Конституции РФ «каждый вправе защищать свои права и свободы всеми способами, не запрещенными законом». Исключив показания обвиняемого из числа доказательств, обвиняемый лишится действенного средства защиты от предъявленного обвинения.

С. В. Марасанова предложила установить следующий порядок проверки заявлений подсудимого о применении к нему недозволенных методов ведения следствия: все жалобы о применении недозволенных методов ведения следствия должны быть заявлены заинтересованными лицами в ходе дознания; по всем жалобам должна быть проведена проверка и вынесено соответствующее решение; вопрос о допустимости доказательств по указанным мотивам должен быть окончательно решен на стадии предварительного слушания при наличии возможности обжаловать соответствующее решение [4, с. 389-390]. Данная точка зрения не кажется убедительной и, как справедливо отмечает В. Н. Перекрестов по этому поводу, причины несостоятельности данного положения заключаются «в корпоративной солидарности сотрудников правоохранительных органов, в сложности доказывания и серьезном противодействии разоблачению данных фактов» [5, с. 55].

Для исключения применения незаконных методов ведения следствия А. Д. Назаров предлагает исключить из штата работников следственных изоляторов временного содержания, более того, он предлагает исключить их из штата учреждений здравоохранения и подчинить их аппарату Уполномоченного по правам человека в Российской Федерации. При этом ежедневно, а также перед и после каждого допроса проводить медицинское освидетельствование заключенного [6, с. 48-49]. Данное предложение является весьма эффективным для исключения насилия на этапе предварительного следствия, но бесполезным, чтобы оградить обвиняемого от других незаконных методов, таких как психическое насилие, нанесение нравственных страданий, обращение, унижающее человеческое достоинство, шантаж, угроза.

В. К. Случевский писал в этой связи: «Психическое принуждение, учиненное над последним (обвиняемым) путем предложения ему вопросов, рассчитанных на введение его в заблуждение относительного значения допроса, а также вопросов, предсказывающих ему ответы, может оказаться не менее опасным для правосудия, нежели принуждение физическое» [7, с. 368].

А. С. Барабаш предлагает п. 1 ч. 2 ст. 74 УПК РФ сформулировать в следующей редакции: «В качестве доказательств допускаются показания подозреваемого, обвиняемого, в которых они свидетельствуют о своей невиновности». Таким образом признаваться допустимыми будут только такие показания, в которых обвиняемый или подозреваемый свидетельствуют о своей невиновности, а показания, в которых они свидетельствуют о своей виновности, не будут являться доказательствами вообще $[8$, с. 45-48].

На наш взгляд, предлагаемое решение проблемы будет весьма әффективным, поскольку в данном случае должностные лица, заблуждающиеся относительно процессуальной значимости признательных показаний обвиняемого, будут лишены

\section{Baikal Research Journal}

электронный научный журнал Байкальского государственного университета 
мнимой цели любыми способами получить признание обвиняемого. Обвиняемый не будет лишен такого действенного механизма защиты от обвинения, как право давать показания, и будет целесообразно спрашивать у обвиняемого, признает ли он себя виновным в начале допроса. Если же он признает себя виновным в совершении преступления, то его показания не будут носить доказательственного значения, но будут являться ценным информативным источником для производства последующих следственных действий. Как правильно отмечали Н. С. Алексеев и В. З. Лукашевич, при условии соблюдения требований закона допрос сознавшегося обвиняемого также может указать на не менее важные сведения, которые укажут на другие доказательства его виновности [9, с. 157-158].

Представляется, что с мнением А. Н. Соловьевой и В. Н. Перекрестова $[10$, с. 56] относительно того, что исключение признательных показаний обвиняемого будет нецелесообразным и неправомерным, так как это может повлечь нарушение прав обвиняемого, трудно согласиться. Обвиняемый будет отстаивать свои права и законные интересы, отрицая свою вину, тем самым он будет защищен от применения к нему насилия со стороны недобросовестных сотрудников правоохранительных органов.

С точки зрения А. Д. Назарова, «вряд ли стоит придавать какой-то особый статус показаниям обвиняемого» $[11$, с. 30]. С его точки зрения многие элементы правового регулирования уголовно-процессуальных отношений связаны с признательными показаниями обвиняемого. Именно при назначении наказания при наличии смягчающих обстоятельств (ст. 61, 62 УК РФ); при явке с повинной (ст. 142 УПК РФ), а также при активном способствовании раскрытию и расследованию преступления, изобличению и уголовному преследованию других соучастников преступления, розыску имущества, добытого в результате преступления; прекращении уголовного преследования в связи с деятельным раскаянием (ст. 28 УПК РФ); при особом порядке принятия судебного решения при согласии обвиняемого с предъявленным ему обвинением (гл. 40 УПК РФ); прекращении уголовного дела в связи с примирением сторон (ст. 25 УПК РФ); заключении досудебного соглашения о сотрудничестве (гл. 40.1 УПК РФ) возникает вопрос: повлияет ли исключение признательных показаний обвиняемого из числа доказательств на другие уголовно-процессуальные институты?

Согласно диспозиции ч. 1 ст. 142 УПК РФ явка с повинной - это добровольное сообщение лица о совершенном им преступлении. В п. 43 ст. 5 УПК РФ законодатель приравнивает явку с повинной к сообщению о преступлении. Первым и основным признаком явки с повинной, несомненно, является добровольность, т. е. лицо, совершившее преступление, опираясь на свои личные мотивы, а не под давлением сотрудников правоохранительных органов, сообщает о совершенном им преступлении. Второй признак явки с повинной заключается в том, что данное сообщение должно быть доведено до сведения органов, уполномоченных рассматривать подобные заявления о преступлении. Таким образом, если лицо, совершившее преступление, изъявит желание явиться с повинной, для этого не требуется его признательных показаний.

Что касается деятельного раскаяния, то в УПК РФ не дается определения такому понятию, так как оно является одним из оснований прекращения уголовного преследования. Согласно ч. 1 ст. 28 УПК РФ суд, а также следователь с согласия руководителя следственного органа или дознаватель с согласия прокурора вправе прекратить уголовное преследование в отношении лица, подозреваемого или обвиняемого в совершении преступления небольшой или средней тяжести, в случаях, предусмотренных ч. 1 ст. 75 УК РФ. Можно выделить следующие признаки деятельного раскаяния:

- лицо, впервые совершило преступление небольшой или средней тяжести;

- лицо добровольно явилось с повинной;

\section{Baikal Research Journal}

электронный научный журнал Байкальского государственного университета 
- способствовало раскрытию и расследованию преступления;

- возместило причиненный ущерб или иным образом загладило вред, причиненный в результате преступления;

- отсутствие возражений лица в отношении которого прекращается уголовное преследование.

Из этого следует, что признание обвиняемым своей вины, так же как и его признательные показания, не имеют уголовно-процессуального значения для деятельного раскаяния.

Согласно ст. 314 УПК РФ обвиняемый вправе при наличии согласия государственного или частного обвинителя и потерпевшего заявить о согласии с предъявленным ему обвинением и ходатайствовать о постановлении приговора без проведения судебного разбирательства по уголовным делам о преступлениях, наказание за которые, предусмотренное УК РФ, не превышает 10 лет лишения свободы. На этом основании можно установить следующие признаки особого порядка принятия судебного решения при согласии обвиняемого с предъявленным ему обвинением:

- согласие государственного или частного обвинителя на применение особого порядка принятия судебного решения;

- согласие потерпевшего на применение особого порядка принятия судебного решения;

- согласие обвиняемого с предъявленным ему обвинением;

- наказание за совершенное преступление не превышает 10 лет лишения свободы;

- осознание обвиняемым характера и последствий заявленного ходатайства о применение особого порядка принятия судебного решения;

- ходатайство было заявлено добровольно и после проведения консультаций с защитником.

Особого внимания заслуживает согласие обвиняемого с предъявленным обвинением. Существуют различные точки зрения по этому поводу. Так, одни ученые [12-15] отождествляют понятия «согласие с предъявленным обвинением» и «признание вины». Другие авторы $[16 ; 17]$ разграничивают данные понятия, так, в частности, Д. П. Великий отмечает: «Признание своей вины содержит элементы покаяния, стремление примериться с обществом, потерпевшим, характеризует личность обвиняемого и в определенных случаях может служить обстоятельством, смягчающим ответственность» $[18$, с. 75$]$. При этом он отмечает: «обвиняемый, отказавшийся давать какие либо показания на предварительном расследовании и, соответственно, не высказавшийся о своей виновности, формально не лишен права заявить ходатайство об особом порядке. Логика очевидна: ознакомившись с материалами следствия, обвиняемый решил, что выгоднее использовать особый порядок, и в этом случае он должен согласиться с предъявленным обвинением» [Там же, с. 76].

Как верно отмечает Н. М. Хромова, обвиняемый вполне может направить ходатайство о рассмотрении уголовного дела в особом порядке и заявить о согласии с предъявленным обвинением, и в то же время не признать свою вину, и вообще он может не давать показаний, и при этом не спорить с обвинением [19, с. 112]. Такой же точки зрения придерживается и А. Г. Калугин, утверждая, что отказ подсудимого от дачи показаний не может являться основанием для отказа в удовлетворении ходатайства о рассмотрении уголовного дела в особом порядке принятия судебного решения при согласии обвиняемого предъявленным ему обвинением [20, с. 71].

Таким образом, можно сделать вывод о том, что «согласие с предъявленным обвинением» и «признание вины» - два совершенно разных понятия, и для того, чтобы обвиняемому ходатайствовать о постановлении приговора без проведения судебного разбирательства, не обязательно давать признательные показания на досудебной стадии.

\section{Baikal Research Journal}


Согласно ст. 25 УПК РФ «суд, а также следователь с согласия руководителя следственного органа или дознаватель с согласия прокурора вправе на основании заявления потерпевшего или его законного представителя прекратить уголовного дело в отношении лица, подозреваемого или обвиняемого в совершении преступления небольшой или средней тяжести, в случаях предусмотренных ст. 76 УК РФ, если это лицо примирилось с потерпевшим и загладило причиненный ему вред» ${ }^{1}$.

По мнению Б. Б. Самдановой, обязательным условием для начала примирительного процесса является заявление обвиняемого о признании им своей виновности и раскаянии в содеянном, при этом признание обвиняемым своей вины должно рассматриваться не как источник доказательств, а как результат его свободного волеизъявления [21, с. 22-23].

К противоположному мнению склоняется Е. А. Симонова, которая полагает, что «отношение же виновного лица к совершенному преступлению может выражаться в чувстве раскаяния, сожалении о случившемся, самопорицании, признании своей вины и т. д.» [22, с. 137]. Такой же точки зрения придерживается М. А. Галимова, которая считает, что прекращение уголовного дела в связи с примирением сторон не зависит от обязательного условия признания вины обвиняемого [23, с. 95]. Как же решает данный вопрос УПК РФ? Согласно ст. 25 УПК РФ для прекращения уголовного дела в связи с примирением сторон необходимо наличие совокупности следующих условий:

- заявление потерпевшего или его законного представителя прекратить уголовное дело в отношении подозреваемого или обвиняемого;

- совершенное преступление должно быть небольшой или средней тяжести;

- лицо должно примириться с потерпевшим;

- лицо должно загладить причиненный вред.

Пленум Верховного Суда РФ в Постановлении «О применении судами законодательства, регламентирующего основания и порядок освобождения от уголовной ответственности» от 27 июня 2013 г. № 19 обращает внимание судов на то, что при разрешении вопроса об освобождении от уголовной ответственности судам следует также учитывать конкретные обстоятельства уголовного дела, включая особенности и число объектов преступного посягательства, их приоритет, наличие свободно выраженного волеизъявления потерпевшего, изменения степени общественной опасности, совершившего преступление, после заглаживания вреда и примирения с потерпевшим, личность совершившего преступление, обстоятельства, смягчающие и отягчающие наказание.

Исходя из изложенного следует отметить, что уголовно-процессуальный закон не требует признания вины обвиняемого для прекращения уголовного дела в связи с примирением сторон, так же, как и нет обязательных требования о даче признательных показаний обвиняемым. Следовательно, уголовное дело на основании ст. 25 УПК РФ может быть прекращено и в отношении лица, не признающего себя виновным.

29 июня 2009 г. Федеральным законом «О внесении изменений в Уголовный кодекс Российской Федерации и Уголовно-процессуальный кодекс Российской Федерации» №141-ФЗ был введен институт досудебного соглашения о сотрудничестве. Согласно ст. 5 п. 61 УПК РФ досудебное соглашение о сотрудничестве - это соглашение между сторонами обвинения и защиты, в котором указанные стороны согласовывают условия ответственности подозреваемого или обвиняемого в зависимости от его действия после возбуждения уголовного дела и предъявления обвинения.

Исходя из смысла ст. 317.6 УПК РФ для применения особого порядка судебного разбирательства необходимо наличие совокупности трех условий: досудебное согла-

${ }^{1} \mathrm{CПC} «$ КонсультантПлюс».

\section{Baikal Research Journal}

электронный научный журнал Байкальского государственного университета 
шение о сотрудничестве заключено при участии защитника; представление прокурора; подтверждение прокурором активного содействия обвиняемого следствию.

Как верно отмечает в этой связи А. Тимошенко: «...ни в одной норме гл. 40 УПК РФ нет упоминания о необходимости получения от обвиняемого полного признания им своей вины» [24, с. 106].

В заключение хотелось бы отметить, что согласно ст. 51 Конституции РФ «Никто не обязан свидетельствовать против самого себя, своего супруга и близких родственников» и ст. 21 Конституции РФ: «Никто не должен подвергаться пыткам, насилию, другому жесткому или унижающему человеческое достоинство обращению или наказанию» данные нормы носят императивный характер, и в первую очередь они относятся к уголовно-процессуальному законодательству. Исходя из буквального толкования данных норм можно заключить, что обвиняемый в преступлении не обязан давать признательные показания. И никто и ничто не вправе заставить или принудить его к признанию своей вины, тем более, средствами насилия над ним.

\section{Список использованной литературы}

1. Устав уголовного судопроизводства // Российское законодательство X-XX веков : в 9 т. / отв. ред. Б. В. Виленский. - М. : Юрид. лит., 1991. — Т. 8. - С. 119-384.

2. Смолькова И. В. Пытка как «способ получения» признательных показаний обвиняемого / И. В. Смолькова // Адвокатская практика. - 2013. — № 4. - С. 8-11.

3. Куссмауль Р. Исключить показания обвиняемого из числа доказательств / Р. Куссмауль // Российская юстиция. - 2001. - № 7. - С. 52-53.

4. Марасанова С. В. Организационные и процессуальные проблемы деятельности суда присяжных / С. В. Марасанова // «Черные дыры» в российском законодательстве. — 2002. — № 4. - C. 389-390.

5. Перекрестов В. Н. Доказательственная функция признания / В. Н. Перекрестов, Н. А. Соловьева // Российская юстиция. - 2008. - №11. - С. 55-58.

6. Назаров А. Д. Влияние следственных ошибок на ошибки суда / А. Д. Назаров. - СПб. : Юрид. центр Пресс, 2003. - 321 с.

7. Случевский В. К. Учебник русского уголовного процесса / В. К. Случевский. - 3-е изд. испр. и доп. - СПб., 1896. - 368 с.

8. Барабаш А. С. Совершенствование уголовно-процессуального механизма защиты граждан от незаконного насилия со стороны сотрудников правоохранительных органов / А. С. Барабаш // Обеспечение прав и свобод человека и гражданина : материалы Междунар. науч.-практ. конф. Тюмень, 17-18 нояб. 2005 г. : в 5 ч. / под ред. Г. Н. Чеботарева. - Тюмень : Изд-во Тюм. гос. ун-та, 2006. - Ч. 4. - С. 45-48.

9. Советский уголовный процесс / под ред. Н. С. Алексеева, В. З. Лукашевича. - Л. : Изд-во Ленингр. ун-та, 1989. - 472 с.

10. Перекрестов В. Н. Проблема обеспечения гарантий допустимости признательных показаний / В. Н. Перекрестов // Российская юстиция. - 2009. - № 8. - С. 55-56.

11. Назаров А. Д. Деятельность суда в выявлении доказательств, полученных в результате применения недозволенных (незаконных) методов / А. Д. Назаров / Российский судья. 2010. - № 11. - С. 29-31.

12. Гладышева О. В. Особый порядок судебного разбирательства в системе уголовного судопроизводства Российской Федерации / О. В. Гладышева, Н. В. Редькин. - М. : Юрлитинформ, 2008. - $152 \mathrm{c.}$

13. Халиков А. Вопросы, возникающие при особом порядке судебного разбирательства / А. Халиков // Российская юстиция. - 2003. - № 1. - С. 63-65.

14. Глобенко О. А. Показания обвиняемого в современном российском уголовном процессе : автореф. дис. ...канд. юрид. наук : 12.00 .09 / О. А. Глобенко. - Н. Новгород, 2007. - 25 с.

15. Александров А. С. Основание и условия для особого порядка принятия судебного решения при согласии обвиняемого с предъявленным обвинением / А. С. Александров // Государство и право. - 2003. - № 12. - С. 43-52.

16. Уголовно процессуальное право Российской Федерации / Л. А. Воскобитова [и др.] ; отв. ред. П. А. Лупинская. - М. : Юрист, 2004. - 800 с.

\section{Baikal Research Journal}

электронный научный журнал Байкальского государственного университета 
17. Чашин А. Н. Особый порядок судебного разбирательства в уголовном процессе / А. Н. Чашин. - М. : Дело и сервис, 2011. - 128 с.

18. Великий Д. П. Особый порядок судебного разбирательства: теория практика / Д. П. Великий // Журнал российского права. - 2005. - № 6. - С. 74-80.

19. Хромова Н. М. Принцип презумпции невиновности при особом порядке судебного разбирательства / Н. М. Хромова // Журнал российского права. - 2013. - № 6. - С. 107-115.

20. Калугин А. Г. Особый порядок принятия судебного решения при согласии обвиняемого с предъявленным ему обвинением : монография / А. Г. Калугин, М. В. Монид. - Красноярск : Сиб. юрид. ин-т МВД России, 2006. - 187 с.

21. Самданова Б. Б. Проблемы становления и развития института прекращения уголовного дела в связи с примирением потерпевшего с обвиняемым в современном российском уголовном процессе : дис. ... канд. юрид. наук : 12.00.09 / Б. Б. Самданова. - М., 2003. - 148 с.

22. Симонова Е. А. Примирение с потерпевшим в уголовном праве России : дис. ... канд. юрид. наук : 12.00.08 / Е. А. Симонова. - Саратов, 2002. - 217 с.

23. Галимова М. А. Прекращение уголовного дела в связи с примирением сторон в стадии предварительного расследования : дис. ... канд. юрид. наук : 12.00 .09 / М. А. Галимова. Омск, 2004. - $220 \mathrm{c.}$

24. Тимошенко А. Досудебное соглашение о сотрудничестве: оценка эффективности процессуального института / А. Тимошенко // Уголовное право. — 2011. — № 4. - С. 106-111.

\section{References}

1. Articles of criminal procedure. In Vilensky B. V. (ed.). Rossiiskoe zakonodatel'stvo X$X X$ vekov [Russian legislation of 10-20 centuries]. Moscow, Yuridicheskaya literatura Publ., 1991, vol. 8, pp. 119-384. (In Russian).

2. Smolkova I. V. Torture as a "way of obtaining» admissions of the accused. Advokatskaya praktika $=$ Advocate's Practice, 2013, no. 4, pp. 8-11. (In Russian).

3. Kussmaul' R. To exclude testimony of the accused from evidences . Rossiiskaya yustitsiy= Russian Justice, 2001, no. 7, pp. 52-53. (In Russian).

4. Marasanova S. V. Organizational and procedural problems of jury court activity. "Chernye dyry» $v$ Rossiyskom Zakonodatel'stve = «Black Holes» in Russian Legislation, 2002, no. 4, pp. 389-390. (In Russian).

5. Perekrestov V. N., Solov'eva N. A. Evidentiary function of admission. Rossiiskaya yustitsiy = Russian Justice, 2008, no. 11, pp. 55-58. (In Russian).

6. Nazarov A. D. Vliyanie sledstvennykh oshibok na oshibki suda [Impact of mistaken identity on judicial mistakes]. Saint Petersburg, Yuridicheskii tsentr Press, 2003. 321 p.

7. Sluchevsky V. K. Uchebnik russkogo ugolovnogo protsessa [Textbook of Russian Criminal Procedure]. $3^{\text {rd }}$ ed. Saint Petersburg, 1896. 368 p.

8. Barabash A. S. Improving criminal procedure mechanism of defending citizens from unlawful violence on part of law-enforcement officers. In Chebotarev G. N. (ed.). Obespechenie prav $i$ svobod cheloveka i grazhdanina. Materialy mezhdunarodnoi nauchno-prakticheskoi konferentsii. Tyumen, 17-18 noyabrya $2005 \mathrm{~g}$. [Provision of rights and freedoms of mn and citizen. Materials of International Research Conference. Tyumen, November 17-18, 2005]. Tyumen', State University Publ., 2006, pr. 4, pp. 45-48. (In Russian).

9. Alekseyev N. S., Lukashevich V. Z. (eds). Sovetskii ugolovnyi protsess [Soviet Criminal Procedure]. Leningrad State University Publ., 1989. 472 p.

10. Perekrestov V. N. Problem of providing guarantees of admission competences. Rossiiskaya yustitsiy $=$ Russian Justice, 2009, no. 8, pp. 55-56. (In Russian).

11. Nazarov A. D. Operation of courts in investigating evidences obtained as a result of applying inadmissible (illegal) methods. Rossiiskii sud'ya = Russian Judge, 2010, no. 11, pp. $29-31$. (In Russian).

12. Gladysheva O. V., Red'kin N. V. Osobyi poryadok sudebnogo razbiratel'stva $v$ sisteme ugolovnogo sudoproizvodstva Rossiiskoi Federatsii [Special order of judicial examination in the system of criminal procedure of the Russian Federation]. Moscow, Yurlitinform Publ., 2008. $152 \mathrm{p}$.

13. Khalikov A. Issues arising from specific order of judicial examination. Rossiiskaya yustitsiy $=$ Russian Justice, 2003, no. 1, pp. 63-65. (In Russian).

14. Globenko O. A. Pokazaniya obvinyaemogo $v$ sovremennom rossiiskom ugolovnom protsesse. Avtoref. Kand. Diss. [Evidences of the accused in modern Russian criminal procedure. Cand. Diss. Thesis]. Nizhnii Novgorod, 2007. 25 p.

\section{Baikal Research Journal}


15. Aleksandrov A. S. Basis and terms special order of making court decision in view of agreement of the accused with the charge brought. Gosudarstvo i pravo = State and Law, 2003, no. 12, pp. 43-52. (In Russian).

16. Voskobitova L. A. et al.; Lupinskaya P. A. (ed.). Ugolovno protsessual'noe pravo Rossiiskoi Federatsii [Criminal Procedural Law of the Russian Federation]. Moscow, Yurist Publ., 2004. $800 \mathrm{p}$.

17. Chashin A. N. Osobyi poryadok sudebnogo razbiratel'stva v ugolovnom protsesse [Special order of juridical examination in criminal procedure]. Moscow, Delo i servis Publ., 2011. 128 p.

18. Veliky D. P. Special order of judicial examination: theory and practice. Zhurnal rossiysk ogo prava = Journal of Russian Law, 2005, no. 6, pp. 74-80. (In Russian).

19. Khromova N. M. Principle of innocence presumption in terms of special order of judicial examination. Zhurnal rossiyskogo prava = Journal of Russian Law, 2013, no. 6, pp. 107-115. (In Russian).

20. Kalugin A. G., Monid M. V. Osobyi poryadok prinyatiya sudebnogo resheniya pri soglasii obvinyaemogo s pred"yavlennym emu obvineniem [A special order of making court decision in view of plea agreement of the accused with the charge brought to him]. Krasnoyarsk, Siberian State Legal Institute of the Ministry of Internal Affairs of the Russian Federation Publ., 2006. $187 \mathrm{p}$.

21. Samdanova B. B. Problemy stanovleniya i razvitiya instituta prekrashcheniya ugolovnogo dela $v$ svyazi s primireniem poterpevshego s obvinyaemym $v$ sovremennom rossiiskom ugolovnom protsesse. Kand. Diss. [Problems of establishing and developing the institution of criminal case termination in view of conciliation of the aggrieved person with the accused in modern Russin criminal procedure. Cand. Diss.]. Moscow, 2003. 148 p.

22. Simonova E. A. Primirenie s poterpevshim v ugolovnom prave Rossii. Kand. Diss. [Conciliation with the in the Criminal Law of Russia aggrieved person. Cand. Diss.]. Saratov, 2002. $217 \mathrm{p}$

23. Galimova M. A. Prekrashchenie ugolovnogo dela $v$ svyazi s primireniem storon $v$ stadii predvaritel'nogo rassledovaniya. Kand. Diss. [Termination of criminal case in view of conciliation of the parties at the stage of preliminary investigation. Cand. Diss.]. Omsk, 2004. 220 p.

24. Timoshenko A. Pre-trial agreement on cooperation: assessing efficiency of of procedural institution. Ugolovnoe pravo = Criminal Law, 2011, no. 4, pp. 106-111. (In Russian).

\section{Информация об авторе}

Сорокин Глеб Вадимович - аспирант, кафедра уголовного права, криминологии и уголовного процесса, Юридический институт, Байкальский государственный университет, 664003, г. Иркутск, ул. Ленина, 11, e-mail: fourtyin@gmail.com.

\section{Author}

Gleb V. Sorokin - PhD Student, Chair of Criminal Law, Criminology and Criminal Process, Baikal State University, 11 Lenin Str., 664003, Irkutsk, Russian Federation; e-mail: fourtyin@gmail.com.

\section{Библиографическое описание статьи}

Сорокин Г. В. Значение признания вины в российском уголовном судопроизводстве / Г. В. Сорокин // Baikal Research Journal. - 2016. — T. 7, № 5. — DOI : 10.17150/2411$\underline{6262.2016 .7(5) .22}$.

\section{Reference to article}

Sorokin G. V. Significance of confessing guilt in Russian criminal procedure. Baikal Research Journal, 2016, vol. 7, no. 5. DOI : 10.17150/2411-6262.2016.7(5).22. (In Russian).

\section{Baikal Research Journal}

